\title{
JOVENS DIRETORES E SEU PROCESSO DE APRENDIZADO
}

\author{
Prof $^{a}$ Dra. Vera Collaço ${ }^{1}$ \\ PPGT; CEART; UDESC \\ vera.collaco@terra.com.br
}

No texto denominado, em sua tradução para o espanhol, Una Polémica sobre dirección, Constantin Stanislavski aborda a difícil questão sobre a formação do artista, e, no caso em foco, a polêmica girava em torno da formação do (da) encenador(a). O mestre russo afirmava com todas as letras: "Mi experiencia me dice que no se pude crear un director, un director nace"(1988, p. 145). Porém, abrindo o campo para o trabalho pedagógico no qual ele acreditava, Stanislavski observava: "Es posible crear una atmósfera favorable en la cual él pueda desarrollarse". (1988, p, 145). Portanto, na perspectiva stanislavskiana "existen directores que se hacen y directores que nacen" (1988, p. 145).

Gosto muito da frase colocada por De Marinis ao abordar a formação do (da) diretor(a): "[...] se trata de un oficio que no se puede enseñar, sino sólo aprender" (2005, p. 153). Com este aparente jogo de palavras entre ensinar e aprender, De Marinis aponta na mesma direção colocada acima pelas palavras de Stanislavski. Ou ainda com as palavras de Grotowski, que define este ser do espetáculo como sendo "[...] alguien que enseña a los otros algo que el mismo no sabe hacer". Ele continua a descrever esta personagem como alguém que tem um domínio de uma técnica precisa e complexa. Mas, quanto à formação deste atuante cênico ele observa: "Só que não se pode receber essa técnica em escola alguma, a aprendemos só com o trabalho" (2007, p. 214).

Revista "O Teatro Transcende" do Departamento de Artes - CCE da FURB - ISSN 2236-6644 Blumenau, v. 16, n. 2, p. 15-29, 2011. 
De Stanislavski a Grotowski, passando por Meierhold e Barba como colocarei mais a frente, percebe-se uma tênue linha que procura esboçar um processo de formação e ensinamento dos procedimentos cênicos para um (uma) possível candidato (a) a atuar como diretor (a)/encenador (a) no jogo teatral. Ou seja, todos estes mestres, e muitos outros, observam que este é um ofício que se aprende através de um intenso mergulho no universo do fazer, do ver, do observar, não necessariamente nesta ordem.

A palavra "ofício" que utilizo acima, que aparece também na fala do De Marinis e mesmo em Grotowski ao falar em técnica, é uma escolha bastante intencional para definir o ensino-aprendizado deste agente cênico. Aqui se retoma o termo no seu sentido de um "trabalho especializado e que pressupõe um certo grau de habilidade" para lidar com as questões técnicas complexas, com a parte artística e com o coletivo, que pode ser temporário ou mais estável, na elaboração do trabalho teatral. E acredito que esta é uma das vias possíveis e mais "segura" para o aprendizado e para o ensino da disciplina direção/encenação nos meios acadêmicos em nossa contemporaneidade. Ou seja, pensar numa relação professor-aluno nos termos colocado acima, qual seja, o de criar atmosferas propícias ao aprendizado, tal como propôs Stanislavski, ou ainda nas trocas mútuas entre professor-aluno onde nenhum é mestre e nem o outro é aprendiz. Mas, sim, um espaço onde as certezas são colocadas em questionamentos, as leituras subsidiárias do processo podem ser colocadas em duvida, e os grandes mestres compreendidos em sua contemporaneidade, e muitas vezes desconstruídos nesse processo.

Ao pensar a arte da direção como um ofício, chamo a atenção para as palavras que emprego - arte e ofício - estou partindo de um pressuposto que ela pode ser aprendida, e isso implica dedicação, observação, tentativas, aplicação prática, correções de rumo, etc. Ou seja, é uma arte entendida como um ofício que se pode vir a dominar com maior ou menor maestria. Ser um (a) diretor (a) que nasce para este ofício e aquele (a) que é lapidado para exercer com maior ou menor habilidade esta profissão. Desta forma, responderia afirmativamente a um questionamento que está na base das colocações acima: é possível ensinar uma pessoa a dirigir um espetáculo? Esta também é a percepção de

Revista "O Teatro Transcende" do Departamento de Artes - CCE da FURB - ISSN 2236-6644 Blumenau, v. 16, n. 2, p. 15-29, 2011. 
todos, como eu, que se dedicam ao ofício de serem professores de teatro nos cursos avulsos, academias ou universidades.

Antes de avançar na próxima questão, na qual devo apontar questionamentos sobre os procedimentos mais adequados para este processo de ensino-aprendizagem, pautada na fala dos grandes mestres e na experiência que venho desenvolvendo, vou dar alguns nortes situacionais de como este ensino ocorre no curso de Licenciatura e Bacharelado em Teatro na UDESC. Neste curso são oferecidas duas disciplinas, denominadas de Prática de Direção Teatral I e II, que visam iniciar os estudantes nos procedimentos da direção teatral. Estas disciplinas são ofertadas na $7^{\mathrm{a}}$ e $8^{\mathrm{a}}$ fase, ambas com 6 créditos, ou 108 horas/aula. Neste primeiro semestre de 2011 eu ministrei Prática de Direção Teatral I, cuja ementa estabelece: "Histórico da direção teatral. Prática de direção teatral de uma cena. Utilização de material dramático. Direção de atores. Composição da cena". Para atender o proposto na ementa estabeleci o seguinte objetivo geral para este semestre: "Desenvolver a prática criativa da direção teatral através da realização de exercício de direção teatral pelos alunos". Seguido de três objetivos específicos:

a) Desenvolver conhecimentos sobre a função da direção teatral. Elaborar projeto cênico e seu respectivo conceito de direção considerando a análise da dramaturgia e os elementos da poética da interpretação atorial. Planejar a realização do espetáculo teatral. Organizar a equipe de trabalho.

b) Realizar ensaios com o fim de desenvolver o processo criativo com vistas à realização do espetáculo.

c) Apresentar o exercício prático frente ao público e refletir sobre o resultado espetacular. 
Para atingir os objetivos acima estabelecidos a disciplina foi dividida em quatro unidades de trabalho. Tendo uma base de estudos teóricos centralizados nas falas de relevantes encenadores do século XX, e uma grande parte dedicada ao processo prático de trabalho dos (das) jovens diretores (as). Nesta etapa a eles (elas) cabia o papel de planejador, diretor do projeto cênico em suas dimensões conceituais e formais, bem como estruturar uma equipe de trabalho para construir um espetáculo. Ou seja, se apoiar e desenvolver os aspectos referentes a cenografia, figurino, iluminação e musicalização. Cabia a eles também organizar de modo a tirar o máximo aproveitamento do pequeno tempo para a elaboração do trabalho cênico. Assim, tiveram que desenvolver um planejamento ordenador do tempo para elaborar a cena e trabalhar os atores, e desta forma sintetizar o processo num espetáculo acabado.

Neste semestre cursaram a disciplina um total de 15 (quinze) estudantes que elaboraram 13 encenações ${ }^{2}$, sendo que dois trabalhos foram desenvolvidos em duplas respondendo pela direção. Uma das exigências é que os trabalhos ficassem com uma duração média de 20 a 30 minutos. Esta delimitação na duração do trabalho se deve ao tempo que temos para apresentar todas as encenações e que se soma a outra exigência da disciplina, que o trabalho tenha pelos menos três apresentações no final do semestre. E todas estas apresentações concentradas nas duas semanas finais do semestre acadêmico. Para fazer este trabalho duas salas - denominadas de Espaço I e Laboratório I - foram escolhidas pelas diferentes encenações. Estas apresentações se caracterizam como Prova Pública destes alunos, e, neste semestre ocorre de 29 de junho a 10 de julho de 2011. E todas as apresentações são gratuitas e abertas à comunidade de uma maneira geral. Nos dois espaços destinados a estes trabalhos pode caber, variando de acordo com os projetos cenográficos e cênicos criados, uma média de 30 a 50 pessoas por sessão. Observo que estes dois espaços possuem materiais técnicos essenciais para o desenvolvimento dos trabalhos, tais como: refletores - par e micro-elipsoidais - mesa de luz e mesa de som, aparelhagem de som, projetores tipo data show, computador, praticáveis, cadeiras para espectadores, cortinas, etc. O Espaço I tem um pé direito de 5 metros e um mezanino que possibilita outros arranjos cênicos. Os dois espaços possibilitam diferentes arranjos 
cênicos, sendo que o Espaço I oferece maiores possibilidade e alternativas, tal como coxias atrás das cortinas e camarins, sendo que este último espaço pode servir também de local para cena, como ocorre em $O$ Belo Indiferente. Estes dois espaços, portanto, oferecem alternativas cênicas para a criação de diferentes espaços e propostas estéticas tal como ocorre neste conjunto de 13 curtos espetáculos.

Neste artigo objetivo debater os procedimentos adotados para desenvolver estas 13 encenações, bem como pontuar as observações resultantes dos encontros teórico-práticos e dos ensaios realizados, pautando-me por questões relativas à escolha e estrutura dos "textos" encenados, seleção do elenco e equipe técnica, organização do trabalho no espaço/tempo, bem como os diferentes processos de elaboração das encenações.

Como já colocado, está atividade foi desenvolvida ao longo do primeiro semestre de 2011, com um carga horária de 6 créditos semanais. Este trabalho se fazia a partir de um encontro semanal em sala de aula e de encontros das direções com seus respectivos coletivos pelos menos duas vezes por semana, de março até a estreia em junho. Para acompanhar e debater os trabalhos em andamento eu assisti a dois ensaios de cada conjunto, um no início do processo e outro já próximo dos ensaios finais. Este acompanhamento também foi realizado por uma monitora, o que me auxiliou no processo de perceber as dificuldades e facilidades de cada direção e de seu trabalho ${ }^{3}$. Detalhando um pouco mais o processo observo que no encontro semanal, do grande grupo, eu fazia comentários sobre o ensaio que tinha acompanhado. Dando agora um retorno ao conjunto de alunos, pois partia do princípio que todos deveriam saber os processos de seus colegas. Essa troca entre as direções se fez desde o primeiro encontro do semestre, onde cada aluno (a) colocava, para os demais, o seu projeto enquanto ainda "um sonho" ou "um desejo". Esse diálogo constante permitiu que o grupo dialogasse e também pudesse ajudar um ao outro em procedimentos cênicos e/ou técnicos.

Nestes encontros semanais também desenvolvemos leituras e debates que pudessem servir de subsídios aos trabalhos em curso. Evidente que da metade do semestre em diante ficou muito difícil manter uma rotina de leituras paralelas aos trabalhos dos espetáculos.

Revista "O Teatro Transcende" do Departamento de Artes - CCE da FURB - ISSN 2236-6644 Blumenau, v. 16, n. 2, p. 15-29, 2011. 
Pois os (as) diretores (as) começavam o processo de serem consumidos por seu trabalho, de encontrar o prazer e dor da criação de um espetáculo. E além do que esta disciplina não é a única atividade acadêmica do semestre. Entre inúmeras priorizações estava tudo o que dizia respeito ao seu espetáculo, pois para 90\% destas direções era a primeira vez que assumiam a responsabilidade de conduzir um processo de montar um espetáculo. Era preciso estar atenta as dificuldades oriundas desse processo e estar aberta para modificar a proposta da disciplina em função das carências e necessidades destes (as) acadêmicos (as).

Portanto, ministrar esta disciplina é também atuar como direção. É saber se colocar sem interferir ou querer modificar os processos encaminhados pelas diferentes direções. É entender que se "aprende fazendo", de nada adianta a direção/professora falar e querer adiantar erros possíveis/visíveis. Ensinar aqui significa estar perto e ao mesmo tempo saber se colocar de fora, ouvir e respeitar os limites e as riquezas do outro em processo de formação. Fazer o que Pavis (2010, p. 364) sugere que se faça com a encenação/encenador: "ela deve ser visível, porém discretamente, como convém ao charme discreto da boa direção". Pode-se dizer que este trabalho é um aprendizado de direção maravilhoso, além de poder conviver e perceber como os jovens conduzem um processo criativo, que é sempre algo que nos enriquece muito.

Aqui convém falar um pouco sobre este conjunto acadêmico. O grupo estava composto por nove diretoras e seis diretores. Sendo que duas diretoras dirigiram um mesmo trabalho - Quem tem medo de gente -, e igual se deu entre dois diretores - Poseidon Bar. O conjunto é formado de pessoas muito jovens, estão, na sua grande maioria, na faixa dos 20 e poucos anos. E um fator que me parece determinante, eles formam, na sua grande maioria, um ensemble realmente. São colegas, na maioria, desde a primeira fase, e criaram um grau de intimidade e companheirismo que admite críticas e "brigas-cobranças", mas ao mesmo tempo possuem uma capacidade de superar dificuldades e atuar em conjunto como poucas vezes se percebe no meio acadêmico. Eu diria que tive o privilégio de trabalhar/aprender com um grupo de acadêmicos (as) muito especial que está passando pelo CEART neste início de novo século. Para mim eles parecem um respiro de uma

Revista "O Teatro Transcende" do Departamento de Artes - CCE da FURB - ISSN 2236-6644 Blumenau, v. 16, n. 2, p. 15-29, 2011. 
grande possibilidade futura. Eles "brincam" em diferentes estéticas sem medo e/ou sem preconceitos. Estão abertos e absorvendo o mundo cênico/estético/real que se lhes apresenta. Poderia dizer que eles estão de acordo com a seguinte fala de Meierhold:

El deber de un director es saber montar qualquier clase de obra. No tiene derecho a especializarse como los médicos [...]. El director que,sin saber montar comedias o vodeviles, tuviera la pretensión de montar tragediasm se adelantaría al fracaso, pues en el auténtico arte se yuxtaponen siempre lo elevado y lo vil, lo ridículo y lo amargo, lo sombrio y lo luminoso. (1986, p. 145)

Para subsidiar um pouco mais este conjunto de direções trouxe para o debate ou adotei uma conduta que possibilitasse a compreensão de alguns aportes teóricos significativos sobre a encenação teatral. Agora retomo a questão bem acima colocada sobre procedimentos fundamentais na formação de jovens encenadores. Começamos por debater a existência da encenação como uma aporte histórico e datado, essencialmente, do século $\mathrm{XX}$. Comungamos aqui com os diferentes teóricos que partilham a visão histórica da encenação como Bernardt Dort (1977), Patrice Pavis (2010), Sergio Jimenez e Edgar Ceballos (1988), De Marinis (2005), etc. As discussões seguintes passaram pela busca, não definitiva e também histórica, do que vem a ser um (a) encenador/diretor (a), e quais a suas funções no ensemble de criação do espetáculo. Respostas difíceis por serem passíveis de inúmeras abordagens, mas pautei o processo nas leituras que se afinassem com as colocações dos teóricos acima citados, por serem as que me parecem mais condizentes com a realidade que vivemos em nosso processo atual.

Sendo assim, podemos pensar o encenador/diretor do ponto de vista de Stanislavski (1988, p. 145) para quem este ser devia ser dotado das capacidades de atuar como "[...] un director-maestro, un director-artista, un director-escritor, un director-administrador". E complemento esta definição com a seguinte colocação:

Uno de los límites que caracterizam a menudo los discursos sobre la dirección teatral, incluso los elaborados por los mismos directores, es un cierto idealismo: en ellos casi parece que la función de la dirección se explica exclusivamente en el plano artístico-creativo. (De Marinis, 2005, p. 151)

Revista "O Teatro Transcende" do Departamento de Artes - CCE da FURB - ISSN 2236-6644 Blumenau, v. 16, n. 2, p. 15-29, 2011. 
E acrescenta De Marinis numa absoluta concordância com Stanislavski, e creio mesmo com os paradigmas da arte cênica contemporânea:

Un teatro nunca se hace solamente con una colección de espectáculos y así, la vida de un grupo no se reduce nunca sólo al trabajo artístico, sino que consiste en muchas actividades y sobre todo se sostiene sobre una delicada y complexa dinámica de relaciones interpersonales que necesitan un punto de apoyo y de referencia. (2005, p. 151-152)

Ainda no mesmo sentido tem a fala Meierhold para quem o encenador: "Es el organizador de la colectividad, es él quien crea su cohesión y aporta las ideias" (1986, p. 114).

As proposições acima colocadas foram bastante enfatizadas no processo de trabalhos destes jovens encenadores. Eles (elas) eram responsáveis pela encenação. Deviam assumir inúmeras funções ao incorporar este papel. Ou seja, serem artistas criadores, administradores do processo de criação; e serem capazes de reescrever o "texto" da cena, e administrar o conjunto que forma o elenco do espetáculo. Cabia-lhes o papel de organizar sua coletividade para um caminho que os levassem a estruturação de um trabalho a ser apresentado ao público. Meu diálogo era com eles quando ia aos seus ensaios, óbvio que também me reportava aos seus atores e demais elementos da equipe, mas meu diálogo básico e direcional era com os (as) responsáveis pela encenação, ou seja, o (a) diretor (a) teatral. Com isso eu cobrava e exigia deles um posicionamento tal como acima explicitado pelos teóricos que serviram de base ao trabalho deste semestre.

As falas acima apontam para uma figura de líder do (a) encenador (a). O que é apontado por De Marinis como um pensamento também exposto por Barba:

No creo en la vocación del director elegido democráticamente por el grupo. [...] Quales son las cualidades del director? Una necessidad personal que le hace elegir un papel de dominio. [...] El problema principal para un director consiste en encontrar el modo para usar su poder con el fin de estimular y no de ahogar. (Barba apud De Marinis, 2005, p. 152) 
A visão sobre o diretor como a de um líder, capaz de estimular e levar o processo adiante, aparece diferenciado, mas canalizada para o mesmo fim nas falas de Bertolt Brecht para quem a missão de um diretor, que ele denomina de "diretor de ensaios" "consiste en estimular y organizar la productividad de los actores (músicos, pintores y demás)". E afirmava Brecht: "Ensayar es probar. Debe insistir en que siempre se tengan presentes diversas possibilidades" (1976, p. 35). Wekwerth, seguindo os passos de Brecht no Berliner Ensemble, propunha "que a função do diretor do grupo deveria ser: a provocação" (1984, p. 51). Similar a fala de Wekweth se encontra uma fala de Grotowski:

As palavras do diretor são, magicamente, palavras de poder. Devem empurrar. O problema não é explicar de maneira teórica ou descritiva [...]. Assim é necessária uma outra capacidade de lançar observações: as observações que empurram. (2007, p. 224)

Este foi, portanto, uma importante discussão com o ensemble de direção que eu trabalhei. A eles foi cobrado exercer seu papel de direção, mas, também com a mesma ênfase, lhe era solicitada a participação da equipe no processo criativo. E estes procedimentos eram visíveis em quase todos os processos. Em um trabalho foi necessário alertar à diretora que ela estava sendo engalfinhada pelo "grupo", e que era preciso reordenar os papéis. O que foi realizado, e no ensaio posterior já era visível a presença segura da direção, com bom encaminhamento do trabalho. Ao atuar com muita força enquanto diretora, com as inseguranças iniciais, outra direção teve grandes problemas na condução do grupo que se desfez e teve que ser reordenado. Nos demais trabalhos percebia-se a condução, concepção do (a) encenador (a), mas com real espaço para inclusão de outras ideias e aportes.

A liderança trás outras questões também importantes para as relações que se estabelecem num processo de encenação. E aqui mais uma vez me apoio nos autores que serviram de guia para esta reflexão. De Stanislavski passando por Meierhold, Copeau, Brecht, Grotowski, Barba etc, podemos ouvir o ressoar em nossos ouvidos uma mesma 
recomendação sobre a relação entre ator e diretor. Dizia Stanislavski: "Si el director le impone a un actor sus proprios pensamientos, drivados de sus proprios recuerdos emotivos e personales, si le dice: 'Debes actuar así precisamente', ejerce un daño a la naturaleza del actor" (1988, p. 146).

Meyerhold aponta para a mesma direção de Stanislavski, com diferenciação do objetivo final, ele dizia: "No es bueno que el director aborde el trabajo con un plan preestabelecido. Es preciso que sepa sacar partido del imprevisto que puede aportarle el desarrollo de los ensaios". (1986, p. 138). E acrescenta Meyerhold:

No existe un director auténticoq ue sitúe su arte por encima del actor. El actor es en el teatro el elemento principal. El arte de la puesta en escena, la composición de las interpretaciones o la alternancia de la luz y de la música están al servicio de los actores notables, de alta calidad. (1986, p. 139)

Sobre esta questão Grotowski é ainda mais radical, diz ser necessário haver um projeto inicial, que ele chama de "o sonho de um espetáculo", mas para ele só se o encenador "for muito estúpido" vai se pautar apenas por seu projeto. Diz Grotowski: "O projeto é necessário para dar a partida no trabalho; mas, depois chegam as coisas desconhecidas, dos atores emergem coisas ignotas, ao diretor mesmo chegam novas associações, os objetos mostram novas funções possíveis" (2007, p. 222).

Wekwerth também observa com ênfase que "o maior erro que se pode cometer durante a fase preparatória de uma encenação" é, entre outras coisas, "forçar a multiplicidade do material de uma peça à uniformidade de um pensamento" (1984, p. 51).

Assim, concordando com os pensamentos acima expostos, aos jovens diretores (as) foi cobrado um projeto inicial de trabalho ${ }^{1}$. Um sonho que deveria ser minimamente materializado em palavras escritas. Este escrito deveria fazer referência ao que iria ser trabalhado, portanto, pedi a eles um "texto" que viria a ser desenvolvido. E aqui se entendeu por texto em seu significado mais amplo enquanto partitura, interpretação de ações ou escritos. Ou seja, adotamos o que De Marinis (2005) chama de "textos abertos e

Revista "O Teatro Transcende" do Departamento de Artes - CCE da FURB - ISSN 2236-6644 Blumenau, v. 16, n. 2, p. 15-29, 2011. 
sem fábula clara". Estes textos foram modificados no processo, mas, de maneira geral, manteve a semente, acima colocada por Grotowski, que é "o sonho de um espetáculo".

Para encerrar este artigo apresento de modo muito breve, pois muito ainda poderia ser dito sobre estas encenações, as questões referentes ao texto e elenco dos trabalhos.

Das treze encenações, duas foram destinadas ao público infantil: Orra, meu!, e Quem tem medo de gente? A primeira encenação foi elaborada apenas por crianças e adolescentes com as quais a diretora, Eliane dos Santos, trabalha fora da Universidade. A diretora fez uma releitura de Romeu e Julieta trazendo a história para o universo escolar de seu elenco. Caracteriza-se como uma experiência diferente do que normalmente é feito na academia, mas cujo resultado é bastante interessante. Já o elenco da Quem tem medo de gente? é formado por alunas do curso de teatro. Sendo que este trabalho, sob a direção, de Fabiana Lazzari de Oliveira e Maria Eduarda Schappo, é o único que une o trabalho atorial com a linguagem de animação. O texto parte de uma releitura de Puft, o Fantasminha, trazendo a história para o universo da animação. Um jogo cênico que possibilitou uma rica releitura dessa história.

Trabalhar com os colegas de outras fases do Curso de Teatro foi uma característica de quase todas estas encenações, mas trabalhar apenas com esse elenco foi uma escolha de A saudade é como líquido que transborda, ou, para Teresa. Este trabalho dirigido por Anderson Luiz do Carmo, se junta com o trabalho desenvolvido em L.E.G.O, dirigido por Pedro Coimbra, como os dois desenvolveram suas encenações a partir de um "texto" corporal de seus elencos. Porém, Pedro optou por misturar em seu elenco atores de outras fases do curso de teatro e seus colegas diretores atuando como atores. Ambos os diretores construíram um texto cênico tendo por base um forte e significativo trabalho de pesquisa centrado no corpo, na repetição do movimento, na busca de uma imagem que se constrói a partir de gestos emanados de ações não interligadas a um enredo ou história. O que resultou em trabalhos imagéticos de grande impulso cênico.

Revista "O Teatro Transcende" do Departamento de Artes - CCE da FURB - ISSN 2236-6644 Blumenau, v. 16, n. 2, p. 15-29, 2011. 
$\mathrm{Na}$ escolha de elencos mesclados entre outras fases e colegas de direção estão também mais três trabalhos, todos eles organizados a partir de estruturas textuais narrativas. Uma delicadeza dirigida por Juliana Riechel denominada de Chá Preto que buscou inspiração cênica e dramatúrgica nos divertidos manuais de civilidade e etiqueta da década de 1950. Trabalho desenvolvido com suave aparência que mostra a solitária e sofrida vida de três mulheres com vidas perdidas. Com escolha similar de elenco tem o trabalho Rosaura, dirigido por Gabriela Leite. Esta encenação como a anterior, prima pela poética cênica. A Gabriela e a Juliana se pautaram na busca cênica vivaz/poética ao tratar de problemas não tão alegres e suaves. Ainda nesta mesma composição de elencos tem o espetáculo Poseidon Bar, com a direção de Andrés Tissier e Rangel Corrêa. Um trabalho muito forte na exigência corporal do elenco, na medida em que ocorre na cena uma luta livre entre dois atores. Neste trabalho os diretores também buscaram desenvolver na cena uma tessitura poética, especialmente na primeira parte do trabalho.

Tem ainda uma experimentação cênica elaborada com a direção de Carol Janning denominada Tamis, que significa, segundo a diretora uma "peneira de seda muito estreita, também é nome de mulher e no espetáculo tem essa relação entre uma feminilidade que, de alguma forma, é separada - peneirada - de uma outra totalidade". Este trabalho está na fronteira entre teatro e peformance, e foi trabalhado, nos diz Carol a partir de partituras físicas, colagens de textos, criação de textos, imagens e gestos.

Trabalhar apenas com seus colegas diretores foi opção do diretor Helder Antunes ao elaborar seu trabalho denominado Canto a Cabo Verde. Trabalho que se desenvolveu a partir de um poema de mesmo nome. Uma homenagem a um país recém independente, que o diretor exaltou pelos contrastes e pela terra que compõe a cena.

Outro conjunto de encenadores optaram por fazer uma junção de pessoas da comunidade externa ao campus com colegas de curso, como foi o caso de Bastianas.

Revista "O Teatro Transcende" do Departamento de Artes - CCE da FURB - ISSN 2236-6644 Blumenau, v. 16, n. 2, p. 15-29, 2011. 
Trabalho construído a partir de um conto e procura exaltar a cultura brasileira trazendo para a cena um pouco do que seria a nossa riqueza folclórica e imagética.

Por fim, teve os encenadores que optaram por trabalhar com pessoas de fora da universidade, como se deu em: Pequenas Histórias de uma Cidade, dirigido por Aline Porto Quites que tentou aproximar alguns poemas de Bertolt Brecht de "uma cidadezinha que fica em uma distante ilha paradisíaca ao sul do Atlântico". Trabalho que se construiu pautado na contação de histórias. Ainda atuando com atores extra-campus temos Beatriz, que trabalhou com a conhecida atriz Margarida Baird, ou ainda, $O$ Belo Indiferente, que colocou em cena a atriz Juliana Aguiar. Interessante destacar que apenas estes dois últimos trabalhos são monólogos. Sendo que em Beatriz a diretora Ana Paula Beling coloca em cena com muita perspectiva e jogo cênico, três músicos que atuam nos devaneios da personagem central, o que, de certa forma, quebra o monologismo da personagem e multiplica as possibilidades de jogo e relação palco-plateia. E Anderson Barbarotti, com $O$ Belo Indiferente, também procurou romper a barreira da personagem sozinha no palco fazendo-a dialogar com figurino e telefone pendurados em cena, além do público, o que é natural em monólogos. Mas, a intensidade cênica criada para nos desvendar o universo caótico dessa mulher foi bem construído e explorado pelo diretor.

Interessante pensar que são dois monólogos que refletem os universos de duas mulheres em momentos de crise com sua vida pessoal e profissional. Espetáculos que recebem a assinatura direcional de uma mulher e de um homem. E observo que estes dois espetáculos foram o que trabalharam de forma mais sistemática com o que conhecemos como texto teatral.

Como eu disse estes trabalhos podem, e devem, ser analisados de diferentes ângulos ainda, tal como os espaços cênicos preferenciais; a música em cena, que uma boa parte utilizou ao vivo; a construção da cena em si, etc. Mas, para o momento julgo significativo recordar que estes (as) jovens iniciantes no processo de encenação teatral procuraram

Revista "O Teatro Transcende" do Departamento de Artes - CCE da FURB - ISSN 2236-6644 Blumenau, v. 16, n. 2, p. 15-29, 2011. 
desenvolver um processo de trabalho que lhes proporcionasse prazer e ao mesmo tempo um aprendizado cênico. E isso transpareceu nas diferentes etapas dos processos, e, acredito, deve ser perceptível no momento em que os mesmos chegarem aos seus referidos públicos.

\footnotetext{
${ }^{1}$ Em minha vida acadêmica e profissional entrelacei com constância duas áreas de conhecimento: Teatro e História. No ano de 1972 ingressei no curso de História da Universidade Federal de Santa Catarina, neste mesmo ano comecei a fazer teatro amador, como atriz, atuando no espetáculo Catacumba 2000, que foi apresentado no primeiro Teatro de Arena de Santa Catarina o saudoso Teatro Trapiche. A paixão pelo teatro me levou a São Paulo e a ECA/USP, em 1976, onde obtive o titulo de mestre em teatro, com dissertação sobre a história do teatro catarinense. A partir de 1980, eu retorno à Florianópolis e passei a atuar na vida acadêmica da Universidade do Estado de Santa Catarina (UDESC) e na administração cultural, na Fundação Catarinense de Cultura (FCC). Da década de 1980 atuei na administração cultural, seja dirigindo o setor de teatro da FCC ou como diretora do Teatro Ademir Rosa. Ao mesmo tempo em que me envolvia com a administração cultural, também dirigia meu olhar para as questões pedagógicas do teatro, e assim, com um grupo de professores, participei da fundação da primeira Escola de Teatro de Santa Catarina. Nesta escola dirigi o espetáculo Woyzeck, de Buchner. Na década de 1980 dediquei-me a várias atividades: administração cultural, na FCC; ao ensino, no CEART e ao teatro, participando do Grupo Teatro Entre Atos e Retratos, onde era responsável pela direção dos espetáculos. Destas direções destaco: O Inimigo do Povo, de Ibsen; Bella Ciao, de Alberto Abreu e Revolução na América do Sul, de Augusto Boal. A partir de 1986 voltei-me exclusivamente para o curso de Artes Cênicas da UDESC. Neste Centro, por muitos anos, assumi a parte administrativa, sendo Diretora Geral de 1990 a 1998. Ao sair deste cargo, em 1998, decidi que era hora de voltar-me, apenas, ao ensino de teatro. Para tanto era necessário renovar meus conhecimentos. Com isso fui fazer doutorado, e aqui, mais uma vez, uni a História e o Teatro. Meu doutorado foi realizado no programa de História Cultural, da UFSC, com tese em teatro: O teatro da União Operária - Um palco em sintonia com a modernização brasileira, defendida em 2004. E desde então retornei à sala de aula na graduação e nos cursos de mestrado e doutorado em teatro do PPGT/CEART-UDESC.
}

\begin{abstract}
${ }^{2}$ Nesta nota coloco os nomes das direções, por ordem alfabética, e de seus respectivos espetáculos. Aline Porto Quites, direção de: Pequenas histórias de uma cidade; Ana Paula Beling, direção de: Beatriz; Anderson Barbarotti, direção de: O Belo Indiferente; Anderson Luiz do Carmo, direção de: A saudade é como líquido que transborda, ou, para Teresa; Andrés Tissier e Rangel Corrêa, direção de: Poseidon Bar; Carol Janning, direção de: Tamis; Cristina Sanchez, direção de: Bastianas; Eliane Ventura dos Santos, direção de: Orra, Meu!; Fabiana Lazzari de Oliveira e Maria Eduarda Schappo, direção de: Quem tem medo de Gente?; Gabriela Leite, direção de: Rosaura; Helder Antunes, direção de: Canto a Cabo Verde; Juliana Riechel, direção de: Chá Preto; Pedro Coimbra, direção de: L.E.G.O.

${ }^{3}$ Nesta disciplina dispomos também de acompanhamento de monitoria, para auxiliar no desenvolvimento das diferentes etapas desse trabalho. Neste semestre tive o apoio precioso da monitora Amanda Gartner, que fez um trabalho significativo de cuidar da parte do pequeno apoio financeiro que o CEART possibilita à esta disciplina. Ordenou os espaços de ensaios deste conjunto de encenações, articulou todo processo de elaboração do material de divulgação do conjunto dos trabalhos e de cada trabalho individualmente, e ainda me assessorou no acompanhamento aos ensaios dos diferentes trabalhos. Além de elaborar e encaminhar toda parte burocrática, de ofícios de demais papeladas para articular todos os procedimentos necessários para viabilizar estes trabalhos. Como se pode ver foi uma personagem vital para o bom andamento do semestre, sua presença tornou viável efetivar um trabalho individual de treze encenações.
\end{abstract}

\title{
REFERÊNCIAS
}

BRECHT, Bertolt. Escritos sobre teatro. Vol. 2. Buenos Aires: Ediciones Nueva Visión, 1976.

DE Marinis, Marco. En Busca del Actor y del Espectador:Compreender el teatro II. Buenos Aires: Galerna, 2005.

Revista "O Teatro Transcende" do Departamento de Artes - CCE da FURB - ISSN 2236-6644 Blumenau, v. 16, n. 2, p. 15-29, 2011. 
DORT, Bernard. O teatro e sua realidade. São Paulo: Perspectiva, 1977.

GROTOWSKI, Jerzy. O Diretor como Espectador de Profissão. In: FLASZEN, Ludwik e POLLASTRELLI, Carla (Curadoria). O Teatro Laboratório de Jerzy Grotowski 19591969. Textos e materiais de Jerzy Grotowski e Ludwik Flaszen com um escrito de Eugenio Barba. SP: Perspectiva, 2007, p. 212 a 225.

JIMENEZ, Sergio e CEBALlOS, Edgar (org). Tecnicas e Teorias de la Direccion Escenica. México: Editorial Gaceta, 1988.

MEYERHOLD, Vsevolod. Teoria Teatral. Madrid: Editorial Fundamentos, 1986.

PAVIS, Patrice. A Encenação Contemporânea: Origens, Tendências, Perspectivas. São Paulo: Perspectiva, 2010.

STANISLAVSKI, Constantin. Trabajos Teatrales: Correspondencia. Buenos Aires: Editorial Quetzal, 1986.

STANISLAVSKI, Constantin. Una Polémica sobre difrección. In: JIMENEZ, Sergio e CEBALlOS, Edgar. Técnicas y Teorias de la Direccion Escenica. México: Editorial Gaceta, 1988, p. 143 a 154.

WEKERTH, Manfred. Diálogo sobre a encenação: um manual de direção. São Paulo: Hucitec, 1984. 